\title{
Poverty: One of the greatest challenges faced by primary health care providers
}

\author{
Effie Viguiliouk
}

\author{
University of Toronto
}

Poverty, like smoking and hypertension, is an independent risk factor for disease, ${ }^{1,2}$ and health outcomes follow a socioeconomic gradient, where those with lower socio-economic status have poorer health outcomes in comparison to those with higher socio-economic status. The Public Health Agency of Canada defines socio-economic status as the position of an individual group within a society classified by their income, education and occupation, ${ }^{3}$ which is part of several factors called the social determinants of health (Figure 1). This relationship between low socio-economic status and poor health is well-known and has been supported by a substantial amount of research, which is well highlighted in a recent Statistics Canada report on causespecific mortality rates by income quintile. ${ }^{1,2}$ Figure 2 , taken from Dorman et al., ${ }^{1}$ shows a summary of these findings, where each successfully lower income quintile is associated with an increase in age-standardized mortality rates from HIV/AIDS, diabetes, chronic obstructive pulmonary disease (COPD), suicide, malignancy, and all causes. ${ }^{4}$ Given these significant negative health outcomes, it is imperative that primary care providers consider poverty when providing care for patients.

\begin{tabular}{|l|l|}
\hline \multicolumn{2}{|c|}{ Social Determinants of Health } \\
\hline Aboriginal status & Gender \\
\hline Disability & Housing \\
\hline Early life & Income and income distribution \\
\hline Education & Race \\
\hline Employment and working conditions & Social exclusion \\
\hline Food insecurity & Social safety net \\
\hline Health services & Unemployment and job security \\
\hline $\begin{array}{l}\text { Figure 1. } \\
\text { This model on the social determinants of health was developed at a York University Conference held } \\
\text { in Toronto in 2002. } \\
\text { Figure adapted from: Mikkonen et al. }{ }^{9}\end{array}$
\end{tabular}

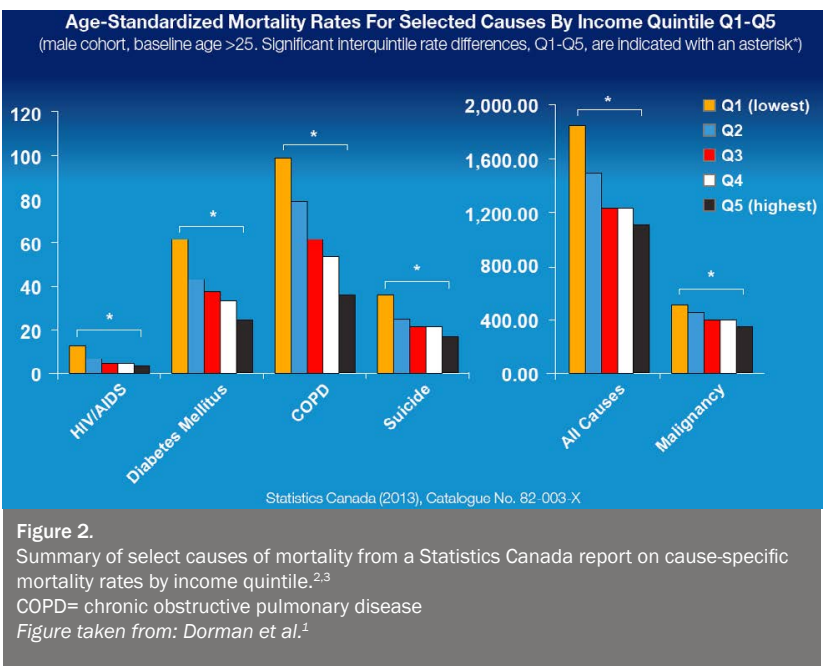

Interventions for poverty, however, are not usually taught during medical training, and physicians may feel overwhelmed when addressing this issue. ${ }^{1}$ Some efforts have been made to help physicians in this regard. For example, physicians from Health Providers Against Poverty (HPAP) in Ontario developed a tool for physicians to screen their patients for poverty and link them with provincial and/or federal programs that can help alleviate the negative health effects of poverty. ${ }^{2,5}$ The Canadian Medical Association (CMA), however, feels that this type of program serves merely as a 'bandage' solution and that physicians should not be placed in this position. ${ }^{5}$ Instead, they suggest cooperation is needed from various governmental departments to focus on addressing this issue. ${ }^{5}$

In order to mitigate the negative health effects of poverty, we need policies in place that will keep people healthy. In fact, socio-economic factors and health care account for $50 \%$ and $25 \%$ of all health outcomes, respectively, ${ }^{7}$ suggesting that changes need to be made outside of the 
C health care system as well. However, over the past 20 years, income inequality has increased in Canada. ${ }^{6}$ At the same time, both the provincial and federal governments have made funding cuts to social programs and services. For example, in January 2013 the Government of Ontario terminated the Community Start-Up and Maintenance Benefit (CSUMB), which helped those receiving social assistance to pay for unexpected housing-related costs. In April 2013, the CMA submitted a set of recommendations on income inequality to the House of Commons Standing Committee on Finance. The aim of these recommendations was to bring awareness and provide the government with ways they could address poverty during policy making. For example, one of their recommendations required that the federal government incorporate a Health Impact Assessment (HIA) as part of Cabinet-policy making. The purpose of an HIA is to provide a "systematic process for making evidence-based judgments on the health impacts of any given policy and to identify and recommend strategies to protect and promote health." Incorporation of such a strategy has already been adopted by several countries and would provide assurance that the government considers the health impacts of its policies, anticipates all possible unintended consequences and takes appropriate corrective action. ${ }^{5}$ The CMA also provided recommendations which addressed required changes within the health sector, such as providing access to uninsured services, such as medication, physiotherapy, occupational therapy, long-term and endof-life care. ${ }^{5}$ Given that 1 in 10 Canadians cannot afford prescription medications, equal access to such services must be provided. Overall, these recommendations reflect the struggles primary care providers face in their daily practice and suggest that these struggles cannot be overcome without the help of the government.

Overall, although efforts have been made to incorporate appropriate tools into medical practice that focus on helping patients in poverty, these may not address the full cause of the issue. We need policies in place to keep individuals healthy, not just ones that will help treat them when they become ill. Cooperation amongst various governmental departments will be required during policy development to put a greater emphasis on poverty and other social determinants of health. Until such changes are made, primary health care providers will continue to face the challenges of poverty in their practice.

\section{References}

1. Dorman K, Pellizzari R, Rachlis M, Green S. Why poverty is a medical problem. Ont Med Rev. 2013 Oct; October 2013:15-19.

2. Ontario College of Family Physicians. Poverty: A clinical tool for primary care in Ontario [brochure]. [Place of publication unknown]: Ontario College of Family Physicians; 2013 [last update unknown; cited 2014 Feb 13]. Available from: http://ocfp.on.ca/docs/default-source/poverty-tool/ poverty-a-clinical-tool-2013-(with-references). pdf?sfvrsn=0.

3. Public Health Agency of Canada. Canada's Response to WHO Commission on Social Determinants of Health [Internet]. [Place of publication unknown]: Public Health Agency of Canada; [date unknown] [updated 2007 May 02; cited 2014 March 21]. Available from: http://www.phac-aspc.gc.ca/sdhdss/glos-eng.php.

4. Tjepkema M, Wilkins R, Long A. Cause-specific mortality by income adequacy in Canada: a 16-year follow-up study. Statistics Canada. 2013;24(7):14-22.

5. Canadian Medical Association. Submission on motion 315 (income inequality, submitted to the House of Commons Standing Committee on Finance) [Internet]. [Place of publication unknown]; $2013 \mathrm{Apr}$ [last update unknown; cited 2014 Mar 21]. Available from:http://www.cma. $\mathrm{ca} /$ multimedia/CMA/Content_Images/Inside_cma/Submissions/2013/ Income-inequality-Brief_en/pdf.

6. Conference Board of Canada. How Canada performs: Income inequality [Internet]. Ottawa (ON); 2013 [last update unknown; cited 2014 Mar 21]. Available from: http://www.conferenceboard.ca/hcp/details/society/ income-inequality.aspx.

7. Senate Subcommittee on Population Health. A healthy, productive Canada: A determinant of health approach [Internet]. [Place of publication unknown]: The Standing Senate Committee on Social Affairs, Science and Technology; 2009 [last update unknown; cited 2014 Feb 14]. Available from: http://www.parl.gc.ca/Content/SEN/Committee/402/popu/rep/ rephealth1jun09-e.pdf.

8. Law MR, Cheng L, Dhalla IA, Heard D, Morgan SG. The effect of cost adherence to prescription medications in Canada. CMAJ. 2012 Feb;184(3):297-302.

9. Mikkonen J, Raphael D, editor. Social determinants of health: The Canadian facts. Toronto: Canadian Scholars' Press Incorporated; 2010.

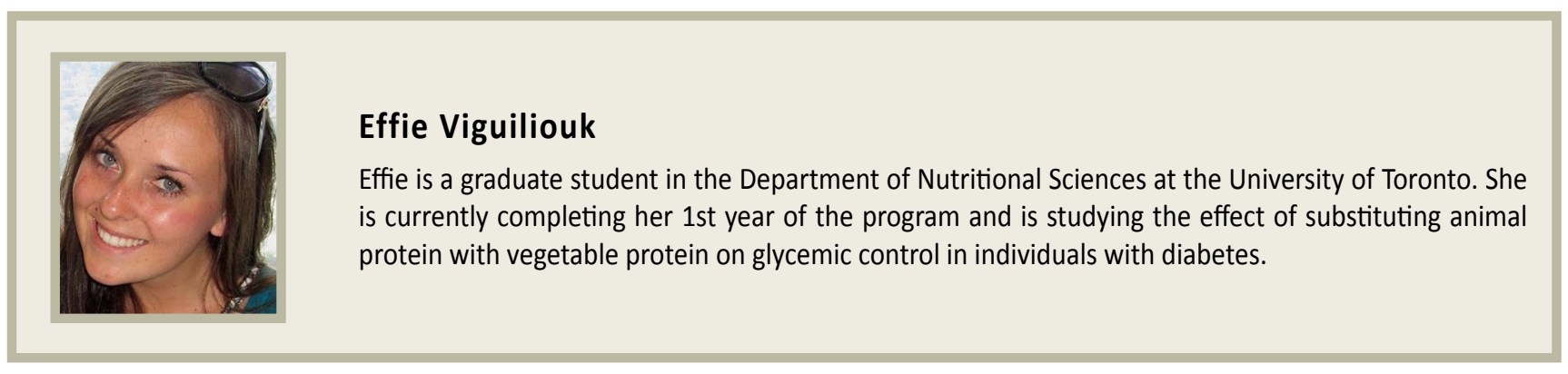

